\title{
Precjepljivanje starih stabala maslina
}

\section{Sažetak}

Istraživanje je obavljeno na stablima maslina sorte Maurino starosti 7 godina. Precjepljivanje je obavljeno sa sortama Buža, Istarska bjelica i Pendolino krajem travnja 2011., stavljanjem plemki pod koru. U nasadu su se tijekom vegetacije obavljale sve potrebne agrotehničke mjere, od međuredne obrade tla do zaštite od bolesti $i$ štetnika. Tijekom vegetacije smo pratili primitak cijepljenja i mjerili vegetativni porast izboja na plemkama po sortama. Također smo pratili utjecaj grana "hraniteljica", od kojih smo neke i prstenovali, na postotak primitka cijepljenja, kao i na vegetativni porast novih izboja. Tijekom jednogodišnjeg praćenja i mjerenja, ustanovili smo da je sorta glavni čimbenik koji utječe na dužinu porasta novih izboja. Postotak primitka je bio 95\%. Kod stabala s ostavljenim granama "hraniteljicama" bilo je manje izboja na primarnim granama i deblu precjepljivanih stabala.

Ključne riječi: precjepljivanje, sorta, hraniteljica, prstenovanje

\section{Uvod}

Precjepljivanje je zahvat kojim se pokušavaju ispraviti greške u voćarstvu kada je potrebno mijenjati sortiment nasada, a da se pritom ne moraju krčiti stabla. Ako su stabla u dobroj kondiciji, precjepljivanje je mnogo jeftiniji način zamjene sorte nego sadnja novog voćnjaka. Promjena sortimenta se najčešće obavlja kada postojeća sorta više nije popularna, odnosno kada se pojavi nova ekonomski isplativija sorta. U masliniku na kojem je provedeno istraživanje ovog rada, precjepljivanje je obavljeno zbog manjka rodnosti postojećih maslina sorte Maurino.

Priprema stabla masline za precjepljivanje se sastoji u skraćivanju primarnih grana za dvije trećine u cilju odstranjivanja već postojećeg uzgojnog oblika. Ovakav način precjepljivanja primjenjuje se kada se u potpunosti želi zamijeniti jednu sortu drugom.

Međutim, u slučaju kad se samo želi dodati sortu oprašivač, nije potrebno precjepljivati sve grane, već se to može obaviti na samo nekoliko grana na krošnji. Rane treba zagladiti voćarskim nožem te obaviti cijepljenje načinom „pod koru“ ili nekim drugim načinom koji je pogodan za cijepljenje kada je podloga deblja od plemke. Tada se ostavljaju pojedine grane privremeno na krošnji kako bi njihovo lišće osiguralo asimilate potrebne za razvoj mladica iz plemki. Svi izboji koji se razvijaju na starom dijelu krošnje se odstranjuju.

\section{Materijali i metode rada}

Istraživanje je započelo 2011. godine. Prilikom precjepljivanja sorte Maurino na nekim stablima puštene su grane hraniteljice, a neke od tih hraniteljica bile su i prstenovane. $S$ obzirom na to, izabrane su tri varijante na kojima se obavljalo istraživanje:

- masline bez grana hraniteljica

- masline s granama hraniteljicama

- masline s granama hraniteljicama koje su prstenovane 
Ukupno su izabrana 22 stabla:

sorta Buža:

- deset stabala koje nemaju granu hraniteljicu

- četiri stabla koja imaju granu hraniteljicu

- četiri stabla koja imaju prstenovanu granu hraniteljicu

sorta Istarska bjelica:

- jedno stablo s hraniteljicom

- jedno stablo s prstenovanom hraniteljicom

sorta Pendolino:

- dva stabla bez hraniteljica.

Kod odabranih stabala označene su mladice na kojima se mjerio vegetativni porast. Mjerenja su obavljana u više navrata tijekom vegetacije pri čemu se koristio metar, a svako stablo ujedno se i fotografiralo.

Maslinik u kojemu je obavljeno istraživanje nalazi se u blizini Zračne luke Pula, površine 1 ha. Nasad je podignut 2006. godine. Uzgojni oblik je polikonična vaza s razmakom sadnje $6 \times 5 \mathrm{~m}$. Sorta je Maurino uzgojena na vlastitom korijenu. Agrotehnički mjere u masliniku sastoje se od međuredne obrade tla, zaštite od bolesti i štetnika te gnojidbe tla. Tijekom vegetacije se obavlja u tri navrata plitka obrada tla, a za gnojidbu se koriste organska gnojiva.

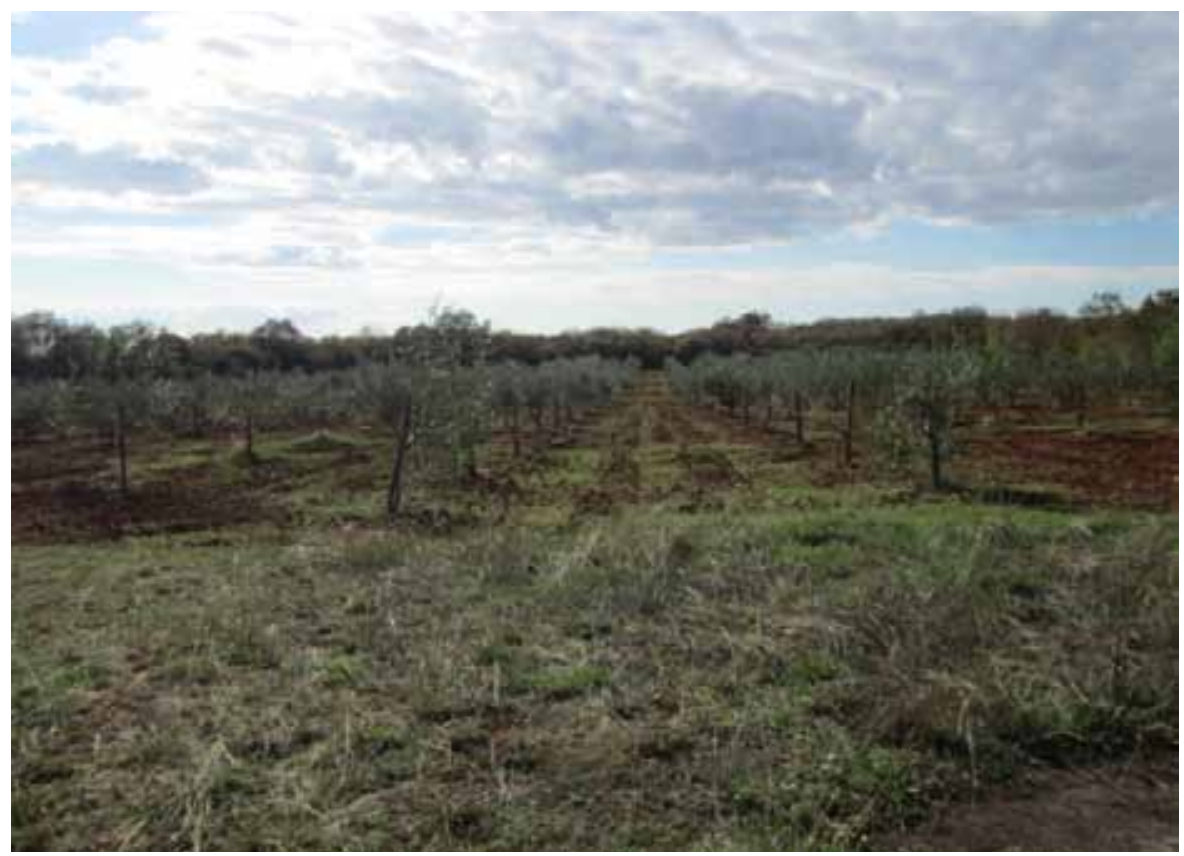

Slika 1. Maslinik u kojemu je obavljeno istraživanje

Figure 1. Olive grove for survey

Prilikom podizanja nasada odabrana je sorta Maurino koja se nije pokazala kao dobar izbor zbog svoje nerodnosti, te je krajem travnja 2011. godine obavljeno precjepljivanje. Na sortu Maurino precijepljene su sorte: Istarska bjelica, Buža i Pendolino. 


\section{Rezultati}

Rezultati obavljenih mjerenja vegetacijskog porasta izboja prikazani su u tablici 1. Porast mladica prikazan je u centimetrima.

Tablica 1. Izmjere vegetativnog porasta izboja

Table 1. Measurement of vegetative growth of shoots

\begin{tabular}{|c|c|c|c|c|c|c|c|c|c|}
\hline Sorta & Tretman & šifra & 5.srp & 20.srp & 7.kol & 28.kol & 16.ruj & 10.lis & 24.stu \\
\hline \multirow{18}{*}{ Buža } & \multirow{10}{*}{$\begin{array}{c}\text { bez } \\
\text { hraniteljice } \\
(\mathrm{cm})\end{array}$} & $1 / \mathrm{V}$ & 110 & 118 & 124 & 124 & 124 & 130 & 136 \\
\hline & & $2 / I I I$ & 90 & 102 & 107 & 107 & 112 & 118 & 123 \\
\hline & & $3 / 11$ & 65 & 80 & 88 & 89 & 89 & 90 & 90 \\
\hline & & $3 / I I I$ & 90 & 100 & 103 & 104 & 104 & 106 & 108 \\
\hline & & $4 / I$ & 58 & 61 & 78 & 87 & 88 & 89 & 96 \\
\hline & & $5 / 1$ & 100 & 115 & 129 & 138 & 144 & 158 & 162 \\
\hline & & $6 / 1$ & 62 & 63 & 100 & 107 & 109 & 110 & 112 \\
\hline & & $7 / I$ & 135 & 139 & 144 & 146 & 146 & 147 & 148 \\
\hline & & 9/II & 120 & 132 & 140 & 142 & 148 & 150 & 155 \\
\hline & & $10 / I I$ & 140 & 146 & 161 & 163 & 166 & 170 & 178 \\
\hline & \multirow{4}{*}{$\begin{array}{l}\text { hraniteljica, } \\
\text { bez prstena } \\
\text { (cm) }\end{array}$} & $11 / I I I$ & 105 & 116 & 123 & 144 & 151 & 154 & 156 \\
\hline & & 19/II & 100 & 110 & 112 & 113 & 115 & 122 & 124 \\
\hline & & 17/III & 83 & 84 & 86 & 86 & 86 & 87 & 87 \\
\hline & & $20 / I I I$ & 40 & 49 & 53 & 53 & 53 & 54 & 54 \\
\hline & \multirow{4}{*}{$\begin{array}{c}\text { hraniteljicas } \\
\text { prstenom } \\
\text { (cm) }\end{array}$} & $13 / I I$ & 89 & 93 & 103 & 106 & 107 & 108 & 109 \\
\hline & & $17 / V$ & 94 & 101 & 108 & 110 & 113 & 124 & 129 \\
\hline & & $4 / 11$ & 60 & 63 & 96 & 103 & 103 & 105 & 107 \\
\hline & & $19 / V$ & 86 & 90 & 94 & 94 & 96 & 99 & 103 \\
\hline \multirow{2}{*}{$\begin{array}{l}\text { Istarska } \\
\text { bjelica }\end{array}$} & $\begin{array}{c}\text { hraniteljica } \\
\text { bez prstena } \\
\text { (cm) }\end{array}$ & $1 / \mathrm{IV}$ & 77 & 81 & 82 & 82 & 82 & 83 & 84 \\
\hline & $\begin{array}{l}\text { hraniteljicas } \\
\text { prstenom } \\
\text { (cm) }\end{array}$ & $2 / I V$ & 96 & 107 & 112 & 112 & 116 & 123 & 128 \\
\hline \multirow{2}{*}{ Pendolino } & & $\mathrm{III} / 8$ & 103 & 116 & 124 & 124 & 130 & 135 & 142 \\
\hline & & III/5 & 83 & 92 & 109 & 113 & 119 & 122 & 128 \\
\hline
\end{tabular}


Tablica 2. Prosjek porasta izboja po terminima $(\mathrm{u} \mathrm{cm})$

Table 2. Average increase of shoots by terms (in $\mathrm{cm}$ )

\begin{tabular}{|c|c|c|c|c|c|c|c|}
\hline PROSJEK & 5.srp & 20.srp & 7.kol & 28.kol & 16.ruj & 10.lis & 24.stu \\
\hline Buža bez hraniteljica & 97 & 105,6 & 117,4 & 120,7 & 123 & 126,8 & 130,8 \\
\hline Buža s hraniteljicom & 82 & 89,75 & 93,5 & 99 & 101,25 & 104,25 & 105,25 \\
\hline $\begin{array}{l}\text { Buža s prstenovanom } \\
\text { hraniteljicom }\end{array}$ & 82,25 & 86,75 & 100,25 & 103,25 & 104,75 & 109 & 112 \\
\hline $\begin{array}{l}\text { Istarska bjelica s } \\
\text { hraniteljicom }\end{array}$ & 77 & 81 & 82 & 82 & 82 & 83 & 84 \\
\hline $\begin{array}{l}\text { Istarska bjelica s } \\
\text { prstenovanom } \\
\text { hraniteljicom }\end{array}$ & 96 & 107 & 112 & 112 & 116 & 123 & 128 \\
\hline $\begin{array}{l}\text { Pendolino bez } \\
\text { hraniteljica }\end{array}$ & 93 & 104 & 116,5 & 118,5 & 124,5 & 128,5 & 135 \\
\hline
\end{tabular}

a)

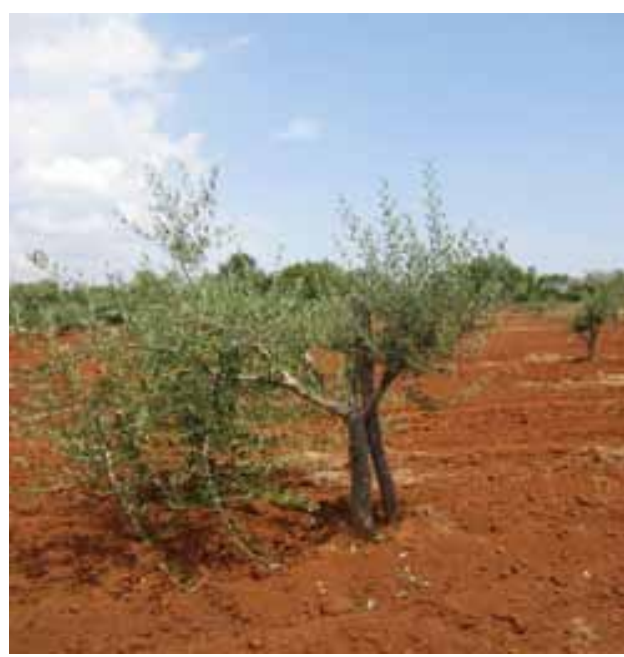

b)

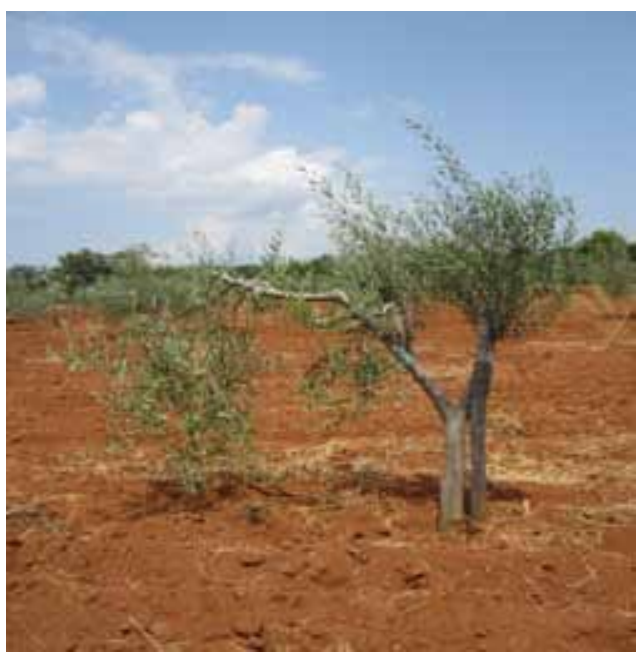

Slika 2. Istarska bjelica (a) i Buža (a) sa prstenovanim hraniteljicama Figure 2. Istrian Bjelica (a) and Buža (a) with ringed feeders 
a)

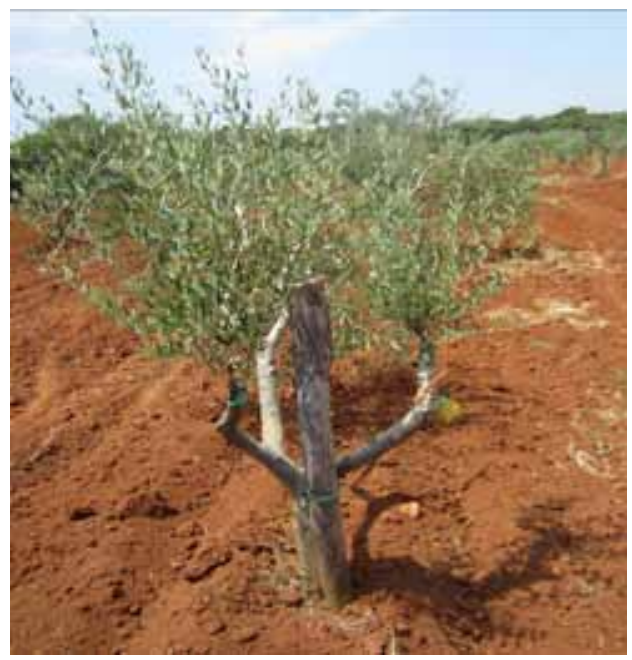

b)

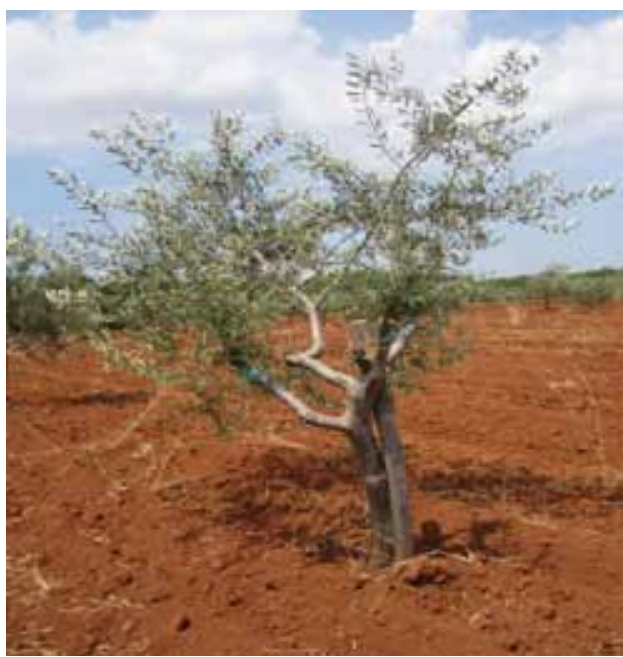

Slika 3. Istarska bjelica (a) i Buža (b) s hraniteljicama koje nisu prstenovane Figure 3. Istrian Bjelica (a) and Buža (b) with non-ringed feeders

a)

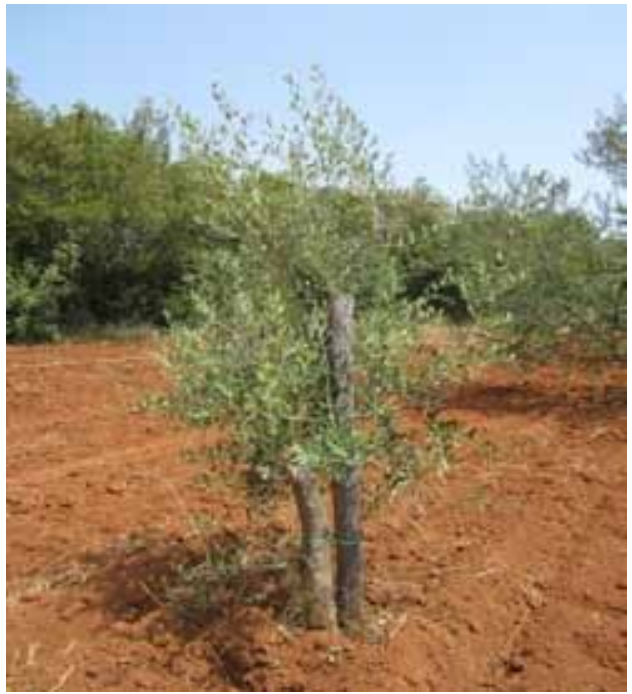

b)

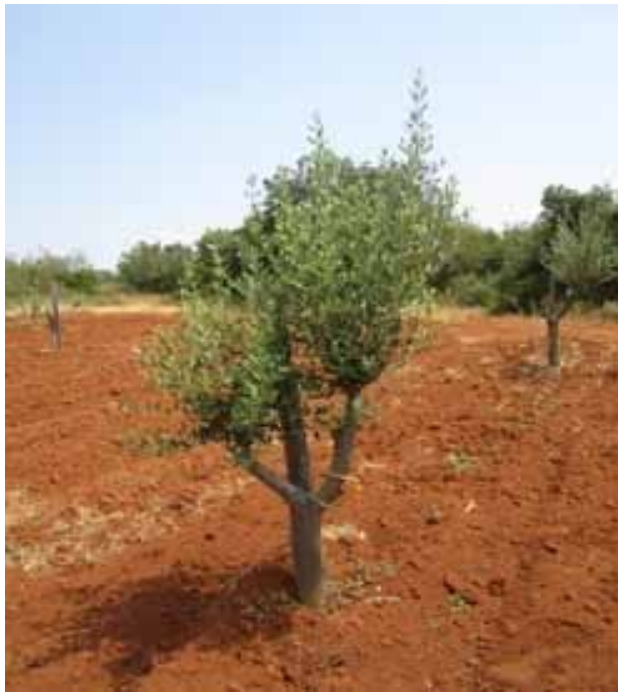

Slika 4. Pendolino (a) i Buža (b) bez hraniteljica

Figure 4. Pendolino (a) and Buža (b) without feeders 
a)

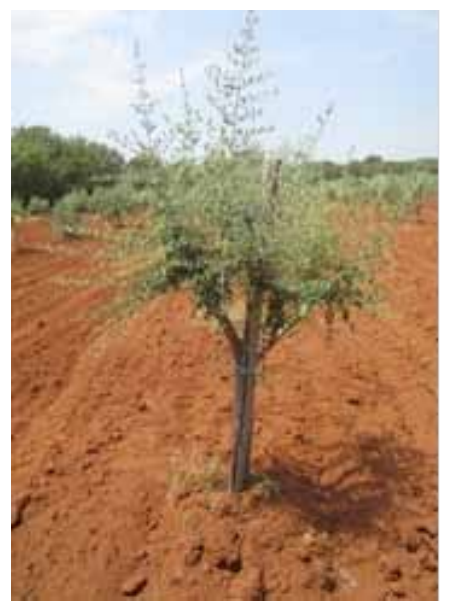

b)

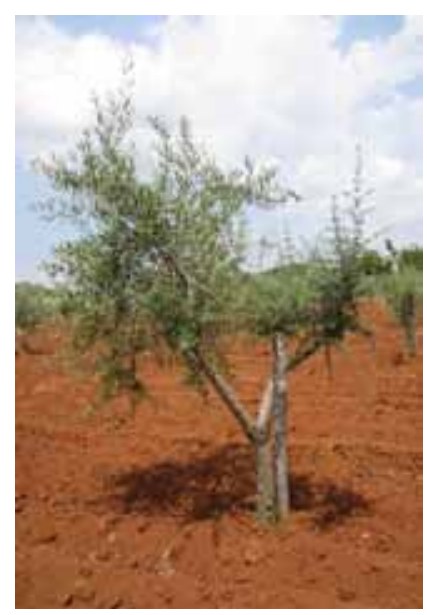

c)

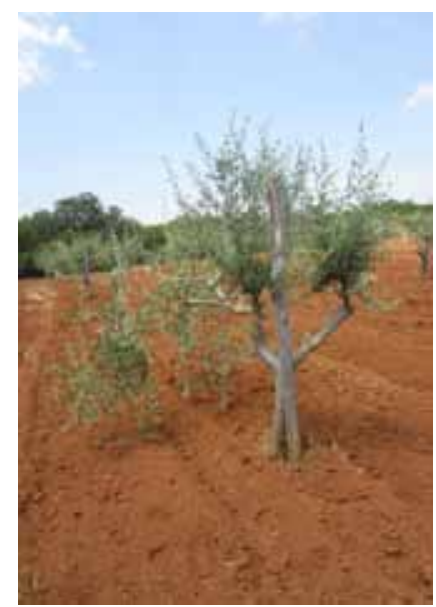

Slika 5. Buža a) bez hraniteljice b) s hraniteljicom c) s prstenovanom hraniteljicom Figure 5. Buža a) without a feeder $b$ ) with a feeders $c$ ) with a Ringed feeders

a)

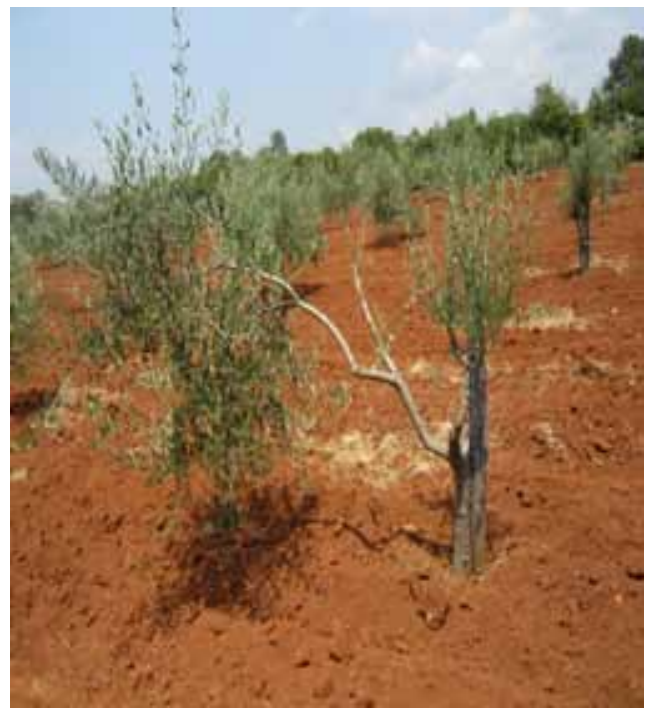

b)

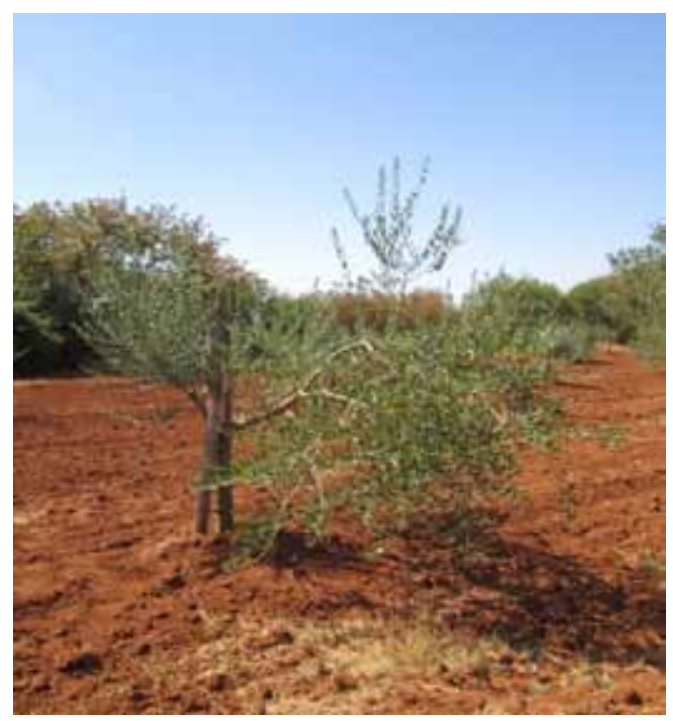

Slika 6. Istarska bjelica s hraniteljicom (a) i Istarska bjelica s prstenovanom hraniteljicom (b)

Figure 6. Istrian Bjelica with a feeder (a) and Istrian Bjelica with feeder (b) 


\title{
Zaključak
} sljedeće:

usporedbom vegetativnog porasta izboja između sorti Istarska bjelica i Buža, gdje obje varijante imaju prstenovane grane hraniteljice, primijećen je veći porast kod sorte Istarska bjelica;

usporedbom vegetativnog porasta izboja sorti Istarska bjelica i Buža, gdje obje varijante imaju grane hraniteljice koje nisu prstenovane, kod sorte Buža primijećen je veći porast;

kod sorti Buže i Pendolino gdje imamo varijantu bez grana hraniteljica, minimalna je razlika u vegetativnom porastu izboja;

usporedbom Buže bez grana hraniteljica, Buže s granom hraniteljicom te Buže s prstenovanom hraniteljicom najveći vegetacijski porast primijećen je kod Buže koja nema granu hraniteljicu, a kod Buže s prstenovanom hraniteljicom malo je veći porast u odnosu na Bužu koja ima granu hraniteljicu bez prstena;

usporedbom Istarske bjelice s hraniteljicom koja nije prstenovana, te Istarske bjelice s prstenovanom hraniteljicom veći vegetacijski porast primijećen je kod Istarske bjelice s prstenovanom hraniteljicom;

temeljem dobivenih rezultata možemo zaključiti da na vegetativni porast izboja kod precjepljivanja grane hraniteljice nemaju značajan utjecaj. Također možemo zaključiti da na porast izboja utječe i svojstvo pojedinih sorti, kao i sama kondicija stabala koja su precijepljena.

\section{Subculturing of old olive trees}

\begin{abstract}
The research was conducted on the olive variety Maurino in age of 7 years. The reproduction was made from the varieties Buža, Istrian Bjelica and Pendolino at the end of April 2011, by putting the scion under the bark. During the vegetation, all the necessary agrotechnical measures were carried out, from the inter-soil treatment to the protection against diseases and pests. During the vegetation, we monitored the inoculation result and measured the vegetative growth of the varieties scions. We also monitored the influence of the "feeders" branch, some of which we ringed the percentage of successful inoculation as well as the vegetative growth of new scions. During one year of monitoring and measurement, we have found that variety is the main factor affecting the length of the growth of new scions. The percentage of receipt was 95\%. In the trees with the "branches" left, there were fewer scions on the primary branches and the thicket of the sub-cultured trees.

Keywords: sub-culturing, variety, feeders, ringing
\end{abstract}

